Artículo científico

Volumen 31(2):311-328. Mayo-agosto, 2020

e-ISSN 2215-3608, doi:10.15517/am.v31i2.38497

http://www.revistas.ucr.ac.cr/index.php/agromeso

\title{
La producción de gas in vitro para estimar la energía neta de lactancia ${ }^{1}$
}

\section{In vitro gas production to estimate net energy of lactation ${ }^{1}$}

\author{
Jorge Luis Sobalvarro-Mena ${ }^{2}$, Jorge Alberto Elizondo-Salazar ${ }^{3}$, Augusto Rojas-Bourillón ${ }^{4}$
}

1 Recepción: 29 de agosto, 2019. Aceptación: 11 de noviembre, 2019. Este trabajo formó parte del proyecto de investigación inscrito en la Vicerrectoría de Investigación, No. 737-B5-188. Universidad de Costa Rica, San José, Costa Rica.

2 Universidad Nacional Agraria. Sede Juigalpa. Juigalpa, Nicaragua. jorge.sobalvarro@ci.una.edu.ni (https://orcid.org/0000-0003-3529-6705).

3 Universidad de Costa Rica. Facultad de Ciencias Agroalimentarias. Estación Experimental Alfredo Volio Mata e Instituto de Investigaciones Agrícolas. Cartago, Costa Rica. jorge.elizondosalazar@ucr.ac.cr (autor para correspondencia, https://orcid.org/0000-0003-2603-9635).

4 Universidad de Costa Rica. Facultad de Ciencias Agroalimentarias. Centro de Investigación en Nutrición Animal e Instituto de Investigaciones Agrícolas. San José, Costa Rica. augusto.rojas@ucr.ac.cr (https://orcid.org/0000-0002-9834-2361).

\section{Resumen}

Introducción. El contenido energético de los forrajes es limitante para la producción de leche en sistemas de pastoreo, y la energía neta de lactancia es el parámetro más utilizado para expresar los requerimientos energéticos de los bovinos lecheros. Objetivo. Comparar el valor de energía neta de lactancia de alimentos, obtenido a partir de ecuaciones basadas en la producción de gas in vitro, con respecto a lo estimado por el modelo del National Research Council (NRC). Materiales y métodos. El experimento se llevó a cabo de agosto a diciembre del 2017 en el Centro de Investigación en Nutrición Animal de la Universidad de Costa Rica, San José, Costa Rica. Se determinó la producción de gas in vitro en muestras de pasto estrella, ryegrass, ensilado de maíz, morera y concentrado. Se evaluaron cinco ecuaciones que incorporaron la producción acumulada de gas a las 24 horas. Resultados. La producción de gas mostró diferencias $(\mathrm{p}<0,001)$ entre alimentos. El mayor volumen de gas producido y contenido de la energía neta de lactancia $\left(\mathrm{EN}_{\mathrm{L} 1 \mathrm{x}}\right)$ se presentaron con el concentrado. La ecuación 3 mostró la mayor precisión en la estimación de $\mathrm{EN}_{\mathrm{L}}$ que obtuvo el índice de correlación de concordancia mayor $\left(r^{2}=0,92\right)$. La utilización de ecuaciones por tipo de alimento mejoró la precisión en la predicción de $\mathrm{EN}_{\mathrm{L}}$. La ecuación 1 fue más precisa en alimento balanceado, mientras que en ensilado de maíz fue la ecuación 4, y en morera, pasto estrella y ryegrass la ecuación 3. El índice de concordancia de Lin explicó mejor las diferencias en predicción de $\mathrm{EN}_{\mathrm{L}}$ que el índice de correlación de Pearson. Conclusión. La producción de gas in vitro con la aplicación de la ecuación 3, fue un método confiable para estimar el contenido de $\mathrm{EN}_{\mathrm{L} 1 \mathrm{x}}$ en cinco alimentos utilizados en vacas lecheras.

Palabras clave: forrajes, nutrición animal, ganado de leche, digestión ruminal, rumen.

\begin{abstract}
Introduction. The energy content of forages is a limitation for milk production in grazing systems, and the net energy of lactation is the parameter most used to express the energy requirements of dairy cattle. Objective. To compare the net energy of lactation in feeds, obtained from equations based on in vitro gas production, with that estimated by the National Research Council (NRC) model. Materials and methods. The experiment was carried out from August to December 2017 at the Animal Nutrition Research Center of the Universidad de Costa Rica, San Jose, Costa Rica.
\end{abstract}


In vitro gas production was determined in samples of star grass, ryegrass, corn silage, mulberry, and concentrate. Five equations that incorporated accumulated gas production at 24 hours were evaluated. Results. Gas production showed differences $(\mathrm{p}<0.001)$ between feeds. The highest volume of gas produced and content of net lactation energy $\left(\mathrm{NE}_{\mathrm{L}}\right)$ was obtained with concentrate. Equation 3 showed de highest precision for the estimation of $\mathrm{NE}_{\mathrm{L}}$, which also reached the highest concordance correlation index $\left(r^{2}=0.92\right)$. The use of equations by type of feed improved the accuracy for the $\mathrm{NE}_{\mathrm{L}}$ prediction. Equation 1 was more precise in concentrate while in corn silage it was equation 4, and in mulberry, star grass and ryegrass it was equation 3 . Lin's concordance index explained the differences in prediction of $\mathrm{NE}_{\mathrm{L} 1 \mathrm{x}}$ better than the Pearson correlation index. Conclusion. The in vitro gas production technique with the application of equation

3 was a reliable method to estimate the $\mathrm{NE}_{\mathrm{L} 1 \mathrm{x}}$ content in five feeds used in dairy cows

Keywords: forage, animal nutrition, dairy cattle, rumen digestion, rumen.

\section{Introducción}

El contenido de energía de los forrajes es, por lo general, la principal limitante para la producción de leche en los sistemas de producción basados en el pastoreo intensivo (Sánchez, 2007), la energía neta de lactancia $\left(\mathrm{EN}_{\mathrm{L}}\right)$ es el parámetro más utilizado para expresar los requerimientos de mantenimiento, gestación, producción de leche y cambios en las reservas corporales en animales adultos, la cual puede expresarse basado en una o más veces el consumo respecto al mantenimiento (NRC, 2001). La séptima edición del modelo NRC (2001) sigue vigente a la fecha, y es la metodología definida de referencia para los cálculos de energía neta de lactancia de alimentos para vacas lecheras.

El contenido de energía neta de lactancia de los alimentos suministrados a rumiantes, se determina a partir de ecuaciones basadas en la composición de la dieta, para utilizar dichas ecuaciones es necesario realizar diversos análisis de laboratorio, por lo que es un proceso tedioso y costoso.

La técnica de fermentación in vitro con fluido ruminal ofrece una alternativa rápida y menos costosa, la cual complementa los estudios de composición química, puede sustituir las pruebas in vivo y permite evaluar a la vez varios tratamientos en condiciones más controladas (Yáñez-Ruiz et al., 2016).

La fermentación de carbohidratos producen principalmente los ácidos grasos de cadena corta acetato, propionato y butirato, y los gases metano, dióxido de carbono e hidrógeno (Elghandour et al., 2017). Las proteínas y grasas son menos afectadas por el proceso fermentativo y participan en menor proporción en la producción de gas (Getachew et al., 1998).

La producción de gas in vitro se relaciona con la composición química de los alimentos incubados, a 24 h de fermentación, la proteína cruda tiene una influencia negativa y los carbohidratos no fibrosos poseen una relación positiva (Getachew et al., 2004).

La fermentación in vitro de sustratos se lleva a cabo en tres fases, inicia con componentes solubles rápidamente fermentados, continua con la fermentación de la fracción insoluble, ambas fases requieren ser hidratadas y colonizadas por los microorganismos ruminales y por último, el gas producido por el reciclaje de la población microbiana y no por la fermentación del alimento (Cone et al., 1997).

En sus inicios, el volumen de gas producido a presión atmosférica era medido a través del desplazamiento de una jeringa lubricada (Menke y Steingass, 1988). La técnica ha evolucionado para medir el volumen de gas producido mediante sensores de presión a tiempo real en sistemas de expulsión de gases automatizados (Muetzel et al., 2014), estos sensores conectados inalámbricamente a una computadora se regulan en tiempo y presión predefinidos (Cornou et al., 2013). 
El gas que se produce a medida que avanza la fermentación y el perfil de acumulación de gas provee información sobre la digestibilidad del alimento y la cinética de la fermentación (Getachew et al., 1998), lo que permite clasificar los alimentos con base en estos parámetros. La producción de gas a las $24 \mathrm{~h}$ se usa para estimar el valor energético del mismo. La prueba de gas in vitro con licor ruminal se utiliza ampliamente en algunos países con varios fines, por ej. en Alemania, la prueba de gas de Hohenheim es un método oficial para la estimación del contenido de energía neta de lactancia (VDLUFA, 2012). Esta prueba aplicada a alimentos mixtos, forrajes y concentrados para estimar $\mathrm{EN}_{\mathrm{L}}$ mostró una fuerte correlación $\left(\mathrm{r}^{2}>0,90, \mathrm{n}=400\right)$ en el contenido de $\mathrm{EN}_{\mathrm{L}}$ obtenido a partir de la producción de gas in vitro con los valores obtenidos de estudios in vivo (Menke y Steingass, 1988). Bajo este principio varias ecuaciones han sido desarrolladas para la estimación del contenido de $\mathrm{EN}_{\mathrm{L}}$ (Seker, 2002; Sallam et al., 2007; Elmenofy et al., 2012).

Ampliamente se han usado las ecuaciones de Menke y Steingass (1988) para determinar el contenido energético de varios tipos de alimentos con resultados favorables, indicando lo robusto del método. Entre estos, se evaluaron alimentos balanceados, pastos verdes y secos (Seker, 2002; Sherasia et al., 2015), ensilado de maíz (Saricicek, 2010) y en leguminosas (Boga et al., 2014). Sin embargo, estas ecuaciones no han sido comparadas con los valores de $\mathrm{EN}_{\mathrm{L}}$ calculados con el modelo del NRC (2001), el cual es el método comúnmente utilizado en Estados Unidos, Costa Rica y otros países para la determinación de $\mathrm{EN}_{\mathrm{L}}$, por lo que es de interés conocer la concordancia en la estimación de $\mathrm{EN}_{\mathrm{L} 1 \mathrm{x}}$ con las ecuaciones basadas en la producción de gas con el modelo del NRC (2001) en alimentos propios de las dietas de ganado lechero de climas tropicales, como el de Costa Rica.

El objetivo de este trabajo fue comparar el valor de energía neta de lactancia de alimentos a partir de ecuaciones basadas en la producción de gas in vitro, con respecto a lo estimado por el modelo del NRC (2001).

\section{Materiales y métodos}

\section{Ubicación del experimento y origen de los alimentos evaluados}

El experimento se llevó a cabo en el Laboratorio de Bromatología del Centro de Investigación en Nutrición Animal (CINA), ubicado en la Ciudad Universitaria "Rodrigo Facio" de la Universidad de Costa Rica, en San Pedro de Montes de Oca, San José, Costa Rica. En el período experimental que abarcó de agosto a diciembre del año 2017, se realizaron evaluaciones en cuatro fechas separadas por siete semanas, consideradas como repeticiones en el estudio, en las que se evaluó por repetición una muestra duplicada de cada alimento en estudio inoculado con licor ruminal y del testigo con solo el inóculo. Las muestras se deshidrataron y pulverizaron a partículas de $1 \mathrm{~mm}$ de diámetro (AOAC, 2006), y se incubaron muestras de $0,5 \mathrm{~g}$ por frasco.

Los alimentos evaluados se utilizaron habitualmente en la dieta de vacas lecheras en la Estación Experimental de Ganado Lechero Alfredo Volio Mata de la Universidad de Costa Rica, ubicada en el Alto de Ochomogo, provincia de Cartago, a 1542 msnm con las coordenadas 954'40,31" N y 8357’18,84” O y suelo Tipic Dystrandepts (Vásquez, 1982). Estos correspondieron a tres forrajes obtenidos de la Estación Experimental: pasto estrella africana (Cynodon nlefuemsis) de 45 días de edad utilizado en el sistema de pastoreo, ensilado de maíz (Zea mays), morera (Morus alba), correspondiente al forraje de planta entera cosechado a 85 días de edad, y un alimento concentrado de origen comercial formulado para vacas lecheras (87\% de MS; 1,6 Mcal $/ \mathrm{kg}$ de MS y $16 \%$ de PC). Se utilizó como tratamiento testigo, los valores conocidos de composición química y producción de gas in vitro de pasto ryegrass (Lolium perenne) variedad Jumbo, cosechado a 34 días de rebrote. 


\section{Análisis químicos}

Se determinó en cada muestra: proteína cruda con el método de Kjedahl (AOAC, 2006), el contenido de nitrógeno ligado a la fibra en detergente neutro y el nitrógeno ligado a la fibra en detergente ácido (Licitra et al., 1996). Basado en el método de Van Soest se determinó el contenido de fibra en detergente neutro, fibra en detergente ácido y lignina en detergente ácido (AOAC, 2006), el contenido de extracto etéreo (AOCS, 2005), contenido de cenizas y digestibilidad in vitro de la materia seca (Van-Soest et al., 1991).

\section{Extracción de líquido ruminal}

Dos vacas donadoras de licor ruminal se manejaron en pastoreo y alimentadas suplementariamente con una dieta formada por $18 \mathrm{~kg}$ de forraje ensilado, $4 \mathrm{~kg}$ de alimento balanceado, 0,5 $\mathrm{kg}$ de harina de soya, 0,5 $\mathrm{kg}$ de pulpa de cítricos deshidratada y $0,4 \mathrm{~kg}$ de melaza de caña de azúcar. A cada vaca se le extrajo $1000 \mathrm{ml}$ de líquido ruminal, 2 h después de la alimentación (Getachew et al., 2002). El líquido ruminal extraído se filtró con cuatro capas de gasa estéril y se introdujo en dos termos con capacidad de un litro, ambos precalentados, gasificados con $\mathrm{CO}_{2}$ y sumergidos en un termo de cinco litros, en el que se incorporó agua a una temperatura de $39^{\circ} \mathrm{C}$, de manera tal que se mantuviese la temperatura durante el traslado del licor ruminal desde la Estación Experimental Alfredo Volio Mata (Cartago, Costa Rica) al Centro de Investigación en Nutrición Animal (CINA) (San José, Costa Rica), ambos de la Universidad de Costa Rica (UCR).

\section{Preparación de solución e inóculo}

La solución mineral incorporada a los frascos para la inoculación se basó en la prueba de gas Hohenheim, con el método de Menke y Steingass (1988), de la cual se incorporaron $80 \mathrm{ml}$ por frasco de $250 \mathrm{ml}$ a inocular. La solución estaba compuesta por tripticasa en $400 \mathrm{ml}$ de $\mathrm{H}_{2} \mathrm{O}$ con $0,1 \mathrm{ml}$ de solución micromineral, $200 \mathrm{ml}$ de solución búfer, $200 \mathrm{ml}$ de solución macromineral y $1 \mathrm{ml}$ de solución de resazurina, 0,5 g de materia seca de alimento (Cone et al., 1996). El inóculo utilizado fue licor ruminal filtrado con cuatro capas de gaza estéril mantenido a $39^{\circ} \mathrm{C}$ y gasificado con $\mathrm{CO}_{2}$ durante la inoculación en cada frasco previamente calentado, por cada frasco se incorporó $20 \mathrm{ml}$ y $2 \mathrm{ml}$ de solución reductora, la incorporación del inóculo y solución reductora se realizó gasificando $\mathrm{CO}_{2}$.

\section{Determinación de la producción de gas in vitro}

La producción de gas en los cinco alimentos evaluados se determinó desde las 0 a las 48 h de incubación, en duplicado, en el laboratorio de bromatología del CINA-UCR, así como dos blancos, sin sustrato inoculados solamente con licor ruminal. Para la medición del volumen de gas producido se utilizó un sistema inalámbrico basado en principios barométricos, conformado por unidades de botellas de vidrio de $250 \mathrm{ml}$, equipadas cada una con un módulo sensor de presión, temperatura y válvulas electromecánicas que controlan la salida de gas, el cual incluye un microchip y un emisor de señal de radio receptada en una computadora para registrar el volumen con intervalos de tiempo definidos. Este equipo opera con un rango de presión de -10 a 500 psi, resolución de 0,039psi y precisión +/- 0,1\% de los valores medidos (RF ANKOM, s.f.). Durante las incubaciones, los cambios de presión en los frascos de vidrio se midieron como diferencias con respecto a la presión atmosférica ambiental, medida por el sensor de referencia no instalado a frascos, que transmiten el valor inalámbricamente por frecuencia de radio a una computadora con intervalos de 5 min, la acumulación de gas en los frascos se libera automáticamente cuando la presión dentro de la unidad llega a 1,0 psi por encima de la presión ambiental, los datos en la computadora se 
registran y se procesan en tiempo real, generándose gráficos de producción de gas, y una base de datos que se exporta en formato .xls para su análisis posterior. La producción de gas total se corrigió con la producción de gas de la inoculación promedio de los blancos, acorde con lo propuesto por Kamalak et al. (2005).

\section{Transformación de datos de presión acumulada a volumen de gas producido}

Los datos de presión acumulada medidos y registrados en psi, se transformaron a ml, con base en la ley de Avogadro que indica que 1,0 psi equivale a $6,894757293 \mathrm{kPa}, 1$ mol ocupa $22,400 \mathrm{ml}$ a $273,15^{\circ} \mathrm{K}$ y $101,325 \mathrm{kPa}$ en condiciones ambientales estándar, con la siguiente ecuación: $n=p(V / R T)$, donde $n$ : es la producción de gas en mol, p: la presión en $\mathrm{kPa}, \mathrm{V}$ : el espacio ocupado por el gas, t: temperatura en $\mathrm{K}$ y R: constante de gas: 8,314472 $\mathrm{L} \cdot \mathrm{kPa} \cdot \mathrm{K}^{-1} \mathrm{~mol}^{-1}$, la producción de gas= n x 22400 (RF ANKOM, s.f.).

\section{Determinación de la energía neta de lactancia con base en las ecuaciones del modelo del NRC}

Los requerimientos de energía para mantenimiento, gestación, cambios en la condición corporal y de producción de leche se expresan como megacalorías de $\mathrm{EN}_{\mathrm{L}}$ de vacas adultas (NRC, 2001). Para estimar el contenido de $\mathrm{EN}_{\mathrm{LIX}}$, energía neta de lactancia una vez mantenimiento se consideró el consumo de $\mathrm{EN}_{\mathrm{L}}$ con base en el $100 \%$ del requerimiento de $\mathrm{EN}_{\mathrm{L}}$ para el mantenimiento, de los alimentos que se ofertan comúnmente a vacas lecheras, se estimó inicialmente los nutrientes digestibles totales una vez mantenimiento $\left(\mathrm{TND}_{1 \mathrm{x}}\right)$ a partir de la siguiente ecuación:

$\mathrm{TND}_{1 \mathrm{x}}(\%)=\operatorname{tdCNF}+\operatorname{tdPC}+(\operatorname{tdAG} \times 2,25)+\operatorname{tdFDN}-7$ (ecuación a)

Donde:

tdCNF: carbohidratos no fibrosos verdaderamente digestibles, se obtiene con la ecuación:

$\operatorname{tdCNF}=0,98(100+[($ FDN - PCFDN $)+$ PC + EE + cenizas $]) \times$ FAP $($ ecuación b $)$

tdPC = proteína cruda verdaderamente digestible, se obtiene con las ecuaciones:

Para forrajes, tdPCf $=\mathrm{PC} \mathrm{x} \mathrm{e}^{[-1,2 \times(\mathrm{PCFDA} / \mathrm{PC})]}$ (ecuación c. 1$)$

Para alimentos balanceados, tdPCc $=[1-(0,4$ x (PCFDA/PC) $)]$ x PC (ecuación c.2)

Ácidos grasos verdaderamente digestibles, $\mathrm{tdAG}=\mathrm{AG}$, nota si $\mathrm{EE}<1, \mathrm{AG}=0$ (ecuación d)

tdFDN, fibra en detergente neutro verdaderamente digestible, con la ecuación:

tdFDN $=0,75 \times\left(F D N-\right.$ PCFDN - L) x $\left[1-(\mathrm{L} / \mathrm{FDN}-\mathrm{PCFDN})^{0,667}\right]$ (ecuación e)

$\mathrm{ED}_{1 \mathrm{X}}=$ energía digestible una vez mantenimiento $\left(\mathrm{Mcal} \mathrm{kg}{ }^{-1}\right)$

$\mathrm{ED}_{1 \mathrm{x}}=(\mathrm{tdCNF} / 100) \times 4,2+(\mathrm{tdFDN} / 100) \times 4,2+(\mathrm{tdPC} / 100) \times 5,6+(\mathrm{AG} / 100) \times 9,4-0,3$ (ecuación f)

$\mathrm{EM}_{1 \mathrm{X}}=$ energía metabolizable una vez mantenimiento (Mcal kg-1)

$\mathrm{EM}_{1 \mathrm{X}}=\left[1,01 \mathrm{x}\left(\mathrm{ED}_{1 \mathrm{x}}\right)-0,45\right]+0,0046 \mathrm{x}(\mathrm{EE}-3)($ ecuación g.1)

En alimentos con menos de $3 \%$ de EE, se utiliza la siguiente ecuación: 
$\mathrm{EM}_{1 \mathrm{x}}=1,01 \times \mathrm{ED}_{1 \mathrm{x}}-0,45$ (ecuación g.2)

$\mathrm{EN}_{\mathrm{LIX}}=$ energía neta de lactancia $1 \mathrm{vez}$ mantenimiento (Mcal kg-1)

$\mathrm{EN}_{\mathrm{LIX}}=0,703 \times \mathrm{EM}_{1 \mathrm{x}}-0,19+\left(\left[\left(0,097 \times \mathrm{EM}_{1 \mathrm{x}}+0,19\right) / 97\right] \mathrm{x}[\mathrm{EE}-3]\right)($ ecuación h.1)

En alimentos con menos de $3 \%$ de EE, se utiliza la siguiente ecuación:

$\mathrm{EN}_{\mathrm{Llx}}=\left[0,703 \times \mathrm{EM}_{1 \mathrm{x}}-0,19\right]($ ecuación h.2)

Donde:

PCFDN: proteína cruda insoluble en fibra detergente neutro = nitrógeno insoluble en la fibra detergente neutro x 6,25 (ecuación i), PCFDA: proteína cruda insoluble en fibra detergente ácida = nitrógeno insoluble en fibra detergente ácida x 6,25 (ecuación j), FAP: factor de ajuste por procesamiento, 0,94 para ensilado de maíz (ecuación k.1), 1,0 para el resto de los alimentos evaluados (ecuación k.2), AG: ácidos grasos (i.e., EE - 1) (ecuación 1), L: lignina en detergente ácido, EE: extracto etéreo, PC: proteína cruda.

\section{Determinación de la energía neta de lactancia a partir de ecuaciones basadas en la producción de gas}

Para la determinación de $\mathrm{EN}_{\mathrm{Llx}}$, a partir de la producción de gas (PG) acumulada a las 24 horas (ml), obtenida de la incubación in vitro con líquido ruminal a temperatura y presión constante, se utilizaron ecuaciones que incorporan en su planteamiento el contenido de proteína cruda (PC) y el extracto etéreo (EE).

Se contó con veinte ecuaciones basadas en la producción de gas que estimaban el contenido de energía neta de lactancia, de estas se seleccionaron las cinco ecuaciones con mayor precisión en la estimación de $\mathrm{EN}_{\mathrm{L}}$ respecto al método NRC (2001) (Cuadro 1).

Cuadro 1. Ecuaciones utilizadas para estimar la energía neta de lactancia $\left(\mathrm{EN}_{\mathrm{Llx}}\right)$ a partir de producción de gas in vitro. San José, Costa Rica. 2017.

Table 1. Equations used to estimate net energy of lactation $\left(\mathrm{EN}_{\mathrm{Llx}}\right)$ from in vitro gas production. San Jose, Costa Rica. 2017.

\begin{tabular}{ccc}
\hline Ecuac. & Fórmula matemática & Fuente \\
\hline 1 & $\mathrm{EN}_{\mathrm{Llx}} \mathrm{Mcal} \mathrm{kg}^{-1} \mathrm{MS}=0,54+0,0959 \mathrm{PG}+0,0038 \mathrm{PC}+0,0001733 \mathrm{PC}^{2} / 4,184$ & Menke y Steingass (1988) \\
2 & $\mathrm{EN}_{\mathrm{L} 1 \mathrm{x}} \mathrm{Mcal} \mathrm{kg}^{-1} \mathrm{MS}=0,08+0,1101 \mathrm{PG}+0,0022 \mathrm{PC}+0,0161 \mathrm{EE} / 4,184$ & Menke y Steingass (1988) \\
3 & $\mathrm{EN}_{\mathrm{Llx}} \mathrm{Mcal} \mathrm{kg}{ }^{-1} \mathrm{MS}=0,689+0,0134 \mathrm{PG}+0,0771 \mathrm{EE}$ & Seker (2002) \\
4 & $\mathrm{EN}_{\mathrm{Llx}} \mathrm{Mcal} \mathrm{kg}^{-1} \mathrm{MS}=0,205+0,0170 \mathrm{PG}+0,0147 \mathrm{PC}+0,0888 \mathrm{EE}$ & Seker (2002) \\
5 & $\mathrm{EN}_{\mathrm{Llx}} \mathrm{Mcal} \mathrm{kg} \mathrm{MS}^{-1} \mathrm{MS}(2,2+0,136 \mathrm{PG}+0,057 \mathrm{PC}+0,149 \mathrm{EE}) \mathrm{x} \mathrm{2,2/14,64}$ & Sallam et al. (2007) \\
\hline
\end{tabular}

$\mathrm{EN}_{\mathrm{Llx}}$ : energía neta de lactancia 1 vez mantenimiento ( $\left.\mathrm{Mcal} \mathrm{kg}^{-1}\right), \mathrm{MS}$ : materia seca, PG: producción de gas in vitro a 24 horas de incubación, PC: porcentaje de proteína cruda, EE: porcentaje de extracto etéreo / $\mathrm{EN}_{\mathrm{Llx}}$ : net energy of lactation 1 time maintenance (Mcal $\left.\mathrm{kg}^{-1}\right), \mathrm{MS}^{-} \mathrm{dry}$ matter, PG: in vitro gas production in 24 hours of incubation, PC: percentage of crude protein, EE: percentage of ether extract.

\section{Análisis estadístico}

La producción de gas acumulada en intervalos de $2 \mathrm{~h}$, los valores estimados por las cinco ecuaciones a partir de la producción de gas in vitro con licor ruminal y la ecuación a partir de química húmeda por el método NRC (2001), se les realizó análisis de varianza de una sola vía con un modelo general lineal. 
Se creó una base de datos en hojas de cálculo .xls en la que se registraron las variables evaluadas de cada alimento y sus repeticiones que incorporaban la producción de gas acumulada con intervalos de 5 min, composición química de los alimentos evaluados, contenido de energía neta de lactancia con el método NRC (2001), cálculo de las ecuaciones basadas en la PGIV.

Las diferencias estadísticas entre medias individuales se identificaron a través de la prueba de Tukey. Se consideraron significativas las diferencias entre medias con valor de $\mathrm{p}<0,05$. La relación entre los valores estimados de $\mathrm{EN}_{\mathrm{L} 1 \mathrm{x}}$ por el método de referencia (NRC, 2001) y los valores estimados por las cinco ecuaciones basadas en la producción de gas in vitro con licor ruminal acumulado a 24 h se realizó mediante el coeficiente de correlación lineal de Pearson (1895) y el coeficiente de correlación de concordancia de Lin (1989) que estima la reproducibilidad de la estimación de $\mathrm{EN}_{\mathrm{L}}$ respecto al modelo del NRC (2001).

Los análisis estadísticos se realizaron con el software SAS Institute Inc. (2011) considerando la base de datos creada.

\section{Resultados}

\section{Composición química y contenido de energía neta de lactancia}

Los alimentos evaluados respecto a su composición química representaron valores típicos y entre estos, la variabilidad permitió la heterogeneidad en estas características. La menor concentración de proteína cruda la registró el ensilado de maíz y la mayor el pasto ryegrass, el valor de FDN varió con menor contenido en el alimento concentrado y la mayor concentración en pasto estrella, el contenido de carbohidratos no fibrosos fue superior en el alimento concentrado y menor en pasto estrella. El menor contenido de cenizas se encontró en el alimento concentado, mientras que el mayor se obtuvo en pasto ryegrass; la menor proporción de extracto etéreo se obtuvo en el pasto estrella y la mayor en el alimento concentrado. Las concentraciones menores de lignina se registraron en el alimento concentrado y las mayores en el pasto estrella; el contenido de proteína ligada a la fibra en detergente neutro fue superior en morera y menor en el ryegrass, el cual también presentó el menor valor de proteína ligada a la fibra en detergente ácido (Cuadro 2).

El contenido energético de los alimentos evaluados, expresados como megacalorías de energía neta de lactancia, fue mas bajo en el pasto estrella, y el contenido mayor se obtuvo en el alimento concentrado, los valores medios se observaron en ensilaje de maíz, morera y pasto ryegrass, respectivamente (Cuadro 2).

\section{Producción de gas in vitro acumulada}

La producción acumulada de gas in vitro mostró diferencias estadísticas entre los alimentos evaluados al compararlos entre sí, a diferentes horas de incubación, al considerar el análisis de varianza y la prueba de Tukey. Los alimentos evaluados formaron de tres a cinco grupos mediante la prueba de Tukey en los diferentes momentos de evaluación (Cuadro 3).

La prueba de Tukey respecto al volumen de gas acumulado en los cinco alimentos y el inóculo sin sustrato formó de tres a cinco grupos con diferencias significativas $(\mathrm{p}<0,001)$, estos grupos estaban conformados por alimentos con similar potencial fermentativo en los intervalos estudiados.

El alimento concentrado en todos los intervalos registró el mayor volumen de gas producido, el ensilado de maíz a las 4 h de incubación mostró el menor volumen de gas acumulado, el pasto estrella a partir de las 8 h de incubación reportó el menor volumen de gas producido entre los alimentos evaluados. El inóculo, licor ruminal sin 
Cuadro 2. Composición química y contenido de energía neta de lactancia $\left(\mathrm{EN}_{\mathrm{L}}\right)$ de cinco alimentos comúnmente utilizados en la dieta de las vacas en la Estación Experimental Alfredo Volio Mata de la Universidad de Costa Rica. San José, Costa Rica 2017.

Table 2. Chemical composition and net energy of lactation $\left(\mathrm{NE}_{\mathrm{L}}\right)$ of five commonly used feeds in the diets at the Alfredo Volio Mata Experiment Station of the Universidad de Costa Rica. San Jose, Costa Rica. 2017.

\begin{tabular}{cccccc}
\hline Nutriente, \% & Pasto estrella & Ensilado de maíz & Morera & $\begin{array}{c}\text { Alimento } \\
\text { concentrado }\end{array}$ & $\begin{array}{c}\text { Pasto ryegrass } \\
\text { (testigo) }\end{array}$ \\
\hline MS & 25,13 & 23,40 & 18,03 & 90,00 & 83,40 \\
MO & 89,92 & 94,04 & 87,47 & 94,72 & 87,80 \\
PC & 13,52 & 8,77 & 17,47 & 17,94 & 18,56 \\
FDA & 42,22 & 34,91 & 28,51 & 7,10 & 24,20 \\
FDN & 69,82 & 58,39 & 56,48 & 18,10 & 45.50 \\
Cenizas & 10,08 & 5,96 & 12,53 & 5,28 & 12,20 \\
Lignina & 7,01 & 4,78 & 5,68 & 0,07 & 1,00 \\
EE & 2,35 & 2,59 & 2,41 & 5,71 & 3,00 \\
CNF & 9,04 & 26,61 & 37,54 & 57,53 & 21,76 \\
PCFDN & 4,81 & 2,32 & 6,43 & 4,56 & 1,02 \\
PCFDA & 2,38 & 0,81 & 1,69 & 1,13 & 0,14 \\
EN & 1,20 & 1,35 & 1,42 & 1,94 & 1,57 \\
\hline
\end{tabular}

MS: materia seca, MO: materia orgánica, PC: porcentaje de proteína cruda, FDA: fibra en detergente ácido, FDN: fibra en detergente neutro, EE: extracto etéreo, CNF: carbohidratos no fibrosos, PCFDA: proteína ligada a la fibra en detergente neutro, PCFDN: proteína ligada a la fibra en detergente neutro, $\mathrm{EN}_{\mathrm{L}}$ : energía neta de lactancia (Mcal kg-1) acorde a ecuaciones NRC (2001) / MS: dry matter, MO: organic matter, PC: crude protein percentage, FDA: acid detergent fiber, FDN: neutral detergent fiber, EE: ether extract, CNF: non-fibrous carbohydrates, PCFDA: fiber-bound protein in neutral detergent, PCFDN: fiber-found protein in neutral detergent, $\mathrm{EN}_{\mathrm{L}}$ : net energy of lactation (Mcal kg-1 MS) according to NRC equations (2001).

Los forrajes fueron obtenidos de la Estación Experimental y el rye grass corresponde a la variedad Jumbo / Forages were obtained from the Experiment Station and rye grass corresponds to the Jumbo variety.

Cuadro 3. Producción acumulada de gas in vitro $(\mathrm{ml})$ de pasto estrella (Cynodon nlemfuensis), ryegrass (Lolium perenne), morera (Morus alba), ensilado de maíz (Zea mays) y alimento concentrado incubado con licor ruminal. San José, Costa Rica. 2017.

Table 3. Accumulated in vitro gas production ( $\mathrm{ml}$ ) of star grass (Cynodon nlemfuensis), ryegrass (Lolium perenne), mulberry (Morus $a l b a)$, corn (Zea mays) silage, and concentrate incubated with ruminal liquor. San Jose, Costa Rica. 2017.

\begin{tabular}{cccccccc}
\hline Hora & Estrella & $\begin{array}{c}\text { Ensilado de } \\
\text { maíz }\end{array}$ & Morera & Ryegrass & $\begin{array}{c}\text { Alimento } \\
\text { concentrado }\end{array}$ & Blancos & Significancia \\
\hline 4 & $2,35 \mathrm{~b}$ & $2,05 \mathrm{~b}$ & $8,53 \mathrm{ab}$ & $8,53 \mathrm{ab}$ & $13,19 \mathrm{a}$ & $4,32 \mathrm{ab}$ & 0,0203 \\
8 & $4,59 \mathrm{c}$ & $7,62 \mathrm{bc}$ & $18,20 \mathrm{ab}$ & $18,20 \mathrm{ab}$ & $30,94 \mathrm{a}$ & $9,67 \mathrm{bc}$ & 0,0001 \\
12 & $8,55 \mathrm{~d}$ & $16,44 \mathrm{~cd}$ & $25,99 \mathrm{bc}$ & $27,92 \mathrm{~b}$ & $48,97 \mathrm{a}$ & $12,68 \mathrm{~d}$ & $<0,0001$ \\
16 & $15,66 \mathrm{~d}$ & $26,88 \mathrm{c}$ & $33,21 \mathrm{bc}$ & $38,22 \mathrm{~b}$ & $63,13 \mathrm{a}$ & $12,85 \mathrm{~d}$ & $<0,0001$ \\
24 & $25,50 \mathrm{c}$ & $39,60 \mathrm{~b}$ & $41,35 \mathrm{~b}$ & $49,13 \mathrm{~b}$ & $76,49 \mathrm{a}$ & $11,20 \mathrm{~d}$ & $<0,0001$ \\
28 & $28,83 \mathrm{c}$ & $42,03 \mathrm{~b}$ & $42,14 \mathrm{~b}$ & $50,56 \mathrm{~b}$ & $77,74 \mathrm{a}$ & $11,20 \mathrm{~d}$ & $<0,0001$ \\
32 & $32,57 \mathrm{c}$ & $43,18 \mathrm{bc}$ & $42,54 \mathrm{bc}$ & $51,98 \mathrm{~b}$ & $78,48 \mathrm{a}$ & $11,72 \mathrm{~d}$ & $<0,0001$ \\
36 & $36,57 \mathrm{c}$ & $44,76 \mathrm{bc}$ & $43,62 \mathrm{bc}$ & $53,63 \mathrm{~b}$ & $78,20 \mathrm{a}$ & $11,20 \mathrm{~d}$ & $<0,0001$ \\
40 & $39,30 \mathrm{~b}$ & $45,67 \mathrm{~b}$ & $43,85 \mathrm{~b}$ & $54,65 \mathrm{~b}$ & $78,43 \mathrm{a}$ & $11,20 \mathrm{c}$ & $<0,0001$ \\
44 & $42,01 \mathrm{~b}$ & $46,71 \mathrm{~b}$ & $45,04 \mathrm{~b}$ & $56,30 \mathrm{~b}$ & $78,82 \mathrm{a}$ & $10,92 \mathrm{c}$ & $<0,0001$ \\
48 & $43,54 \mathrm{~b}$ & $47,03 \mathrm{~b}$ & $45,10 \mathrm{~b}$ & $56,93 \mathrm{ab}$ & $78,54 \mathrm{a}$ & $11,20 \mathrm{c}$ & $<0,0001$ \\
\hline
\end{tabular}

Valores dentro de una misma fila con diferente letra difieren significativamente $(\mathrm{p}<0,05) /$ Values within the same row with different letter are significantly different $(\mathrm{p}<0.05)$.

Los forrajes fueron obtenidos de la Estación Experimental y el ryegrass corresponde a la variedad Jumbo / Forages were obtained from the Experiment Station and ryegrass corresponds to the Jumbo variety. 
sustrato, a las 12 h de incubación estabilizó su producción de gas, y a partir de ese momento conformó el grupo con menor volumen de gas acumulado. A partir de las 24 h de incubación el ensilado de maíz, morera y pasto ryegras conformaron el grupo intermedio, excepto a las 32,36 y $48 \mathrm{~h}$ que el pasto ryegrass conformó un grupo diferente (Cuadro 3).

\section{Comportamiento de la curva de producción acumulada de gas in vitro}

La producción de gas in vitro mostró un comportamiento típico en los alimentos, en las primeras horas de incubación, la liberación de gas inició de forma lenta, y a partir de las 4 h se observó un crecimiento progresivo del gas acumulado en todos los alimentos en estudio. Los blancos, sin sustrato, detuvieron el proceso fermentativo y se estabilizó a partir de las 16 h de incubación. Desde las 0 h de incubación inició el proceso fermentativo de forma lenta en todos los alimentos; entre alimentos y períodos de incubación se encontraron diferencias significativas $(\mathrm{p}<0,001)$ (Cuadro 3) en las primeras horas el proceso inició de forma lenta y a partir de las 4 h la acumulación de gas se observó más intensa (Figura 1).

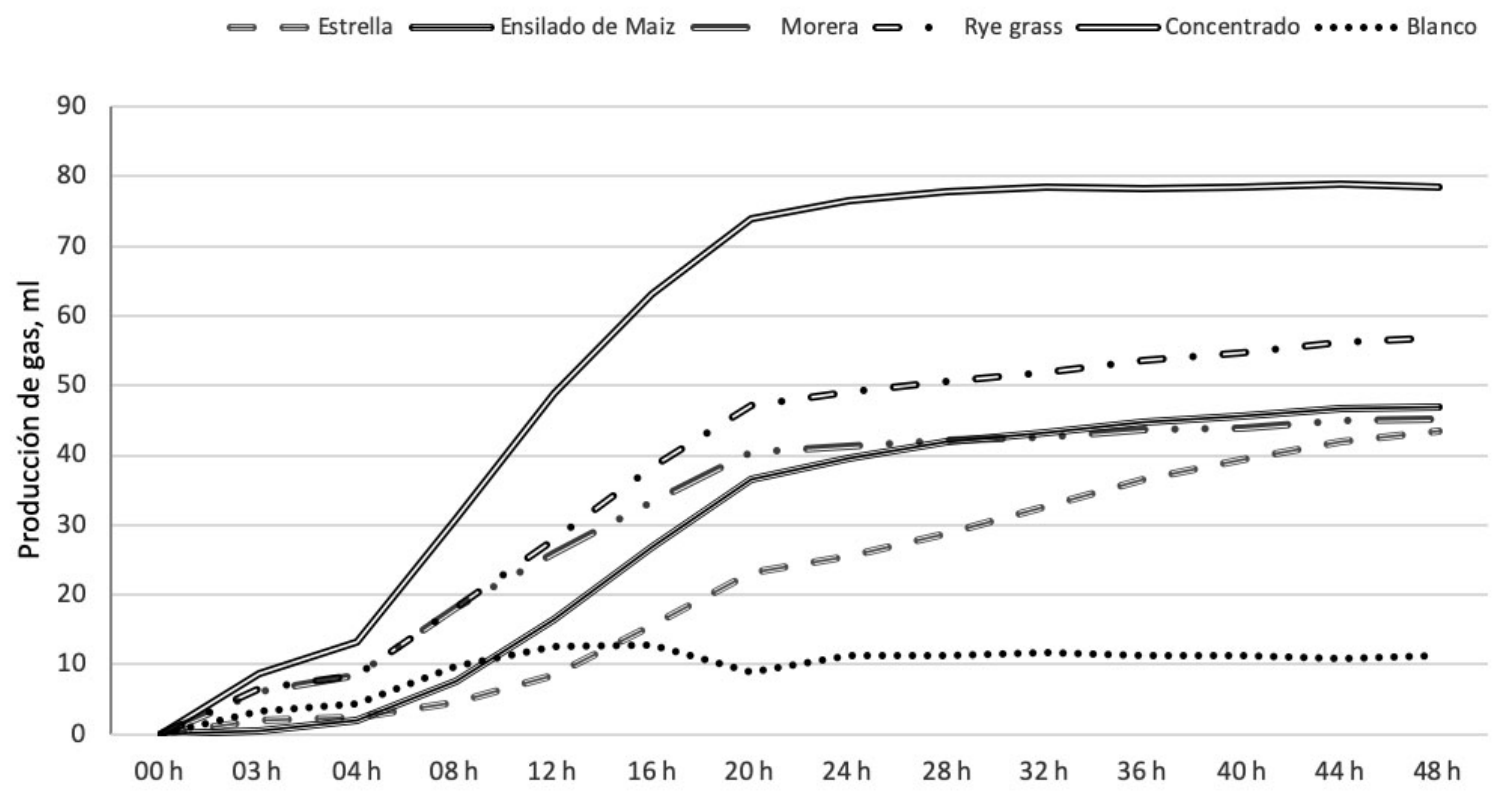

Figura 1. Perfiles de producción acumulada de gas in vitro $(\mathrm{ml})$ de pasto ryegrass, pasto estrella, morera, ensilado de maíz y alimento concentrado incubado con licor ruminal. San José, Costa Rica. 2017.

Los forrajes fueron obtenidos de la Estación Experimental y el rye grass corresponde a la variedad Jumbo.

Figure 1. Cumulative production profiles of in vitro gas $(\mathrm{ml})$ from rye grass, star grass, mulberry, corn silage, and concentrated feed incubated with ruminal fluid. San José, Costa Rica. 2017.

Forages were obtained from the Experiment Station and rye grass corresponds to the Jumbo variety.

El comportamiento fermentativo fue diferente en los alimentos evaluados, el alimento concentrado acumuló el mayor volumen de gas en cada período, la PGIV se estabilizó a las 24 h, y solo acumuló 2,6 \% entre 24 y 48 h de 
incubación. La morera, el pasto ryegrass y el ensilado de maíz mostraron una dinámica fermentativa similar entre ellos, pero distinta al alimento concentrado y al pasto estrella, logrando acumular 91,7, 86,3 y 84,2 \% del total del volumen de gas a las $24 \mathrm{~h}$ de incubación, respectivamente, y a partir de ese momento hasta las $48 \mathrm{~h}$ evaluadas acumularon la proporción restante del total de gas producido. El pasto estrella mostró un comportamiento diferente al resto de alimentos (Figura 1, Cuadro 3), su producción de gas in vitro mostró una tendencia lineal desde el inicio del proceso fermentativo con una leve inflexión a las $12 \mathrm{~h}$, y acumulación de gas de forma lineal y constante hasta las $48 \mathrm{~h}$ evaluadas en este estudio, sin detener en este período la acumulación de gas, de las 24 h y hasta las $48 \mathrm{~h}$ acumuló, relativamente la misma proporción de gas producido en las primeras 24 h (58,6 \%).

\section{Estimación de energía neta de lactancia $\left(\mathrm{EN}_{\mathrm{L}}\right)$ a partir de ecuaciones basadas en la producción de gas in vitro con licor ruminal a 24 horas de incubación}

Los valores estimados de $\mathrm{EN}_{\mathrm{L}}$ en los cinco alimentos estudiados, a partir del modelo del NRC (2001) y de las cinco ecuaciones basadas en la producción de gas in vitro evaluadas, fueron estadísticamente diferentes $(\mathrm{p}<0,001)$ y se agruparon distintamente según la ecuación aplicada, difiriendo en la sensibilidad de clasificación, lo que indica la mayor o menor sensibilidad de cada ecuación para la estimación.

Al aplicar las ecuaciones del modelo NRC (2001) se agrupó a los alimentos en estudio en cinco grupos a partir de la prueba de Tukey, cada alimento representó un grupo diferente (Cuadro 4), en orden descendente el valor de $\mathrm{EN}_{\mathrm{L}}$ fue: alimento concentrado para vacas lecheras, ryegrass, morera, ensilado de maíz y pasto estrella.

Cuadro 4. Energía neta de lactancia $\left(\mathrm{EN}_{\mathrm{L}} \mathrm{Mcal} \mathrm{kg}^{-1} \mathrm{MS}\right.$ ) calculada con el modelo del NRC (2001) y a partir de ecuaciones basadas en la producción de gas in vitro con licor ruminal, de cinco alimentos para vacas lecheras en Costa Rica y porcentajes de predicción de las ecuaciones respecto al modelo NRC (2001). San José, Costa Rica. 2017.

Table 4. Net energy of lactation ( $\mathrm{NE}_{\mathrm{L}} \mathrm{Mcal} \mathrm{kg}{ }^{-1} \mathrm{MS}$ ) calculated with the NRC (2001) model and from equations based on the in vitro gas production with ruminal fluid, of five feeds for dairy cattle in Costa Rica and the percentages of the predicted equations regarding the NRC (2001) model. San Jose, Costa Rica. 2017.

\begin{tabular}{lcccccc}
\hline Alimento & NRC (2001) & Ecuac. 1 & Ecuac. 2 & Ecuac. 3 & Ecuac. 4 & Ecuac. 5 \\
\hline Pasto estrella & $1,20^{\mathrm{e}}$ & $\begin{array}{c}0,72^{\mathrm{c}} \\
(-40,12)\end{array}$ & $\begin{array}{c}0,69^{\mathrm{c}} \\
(-42,56)\end{array}$ & $\begin{array}{c}1,20^{\mathrm{d}} \\
(0,27)\end{array}$ & $\begin{array}{c}1,03^{\mathrm{d}} \\
(13,76)\end{array}$ & $\begin{array}{c}1,01^{\mathrm{d}} \\
(16,09)\end{array}$ \\
\hline Ensilado de maíz & $1,35^{\mathrm{d}}$ & $1,21^{\mathrm{b}}$ & $1,26^{\mathrm{b}}$ & $1,51^{\mathrm{c}}$ & $1,36^{\mathrm{d}}$ & $1,42^{\mathrm{c}}$ \\
& & $(-10,34)$ & $(-6,49)$ & $(12,17)$ & $(0,57)$ & $(5,03)$ \\
\hline Morera & $1,42^{\mathrm{c}}$ & $1,11^{\mathrm{b}}$ & $1,13^{\mathrm{b}}$ & $1,43^{\mathrm{c}}$ & $1,38^{\mathrm{c}}$ & $1,38^{\mathrm{bc}}$ \\
& & $(-22,17)$ & $(-20,73)$ & $(0,62)$ & $(-2,91)$ & $(-2,87)$ \\
\hline Pasto ryegrass & $1,57^{\mathrm{b}}$ & $1,29^{\mathrm{b}}$ & $1,33^{\mathrm{b}}$ & $1,58^{\mathrm{b}}$ & $1,58^{\mathrm{b}}$ & $1,56^{\mathrm{b}}$ \\
& & $(-18,07)$ & $(-15,08)$ & $(0,55)$ & $(0,60)$ & $(-0,59)$ \\
\hline Concentrado & $1,94^{\mathrm{a}}$ & $1,91^{\mathrm{a}}$ & $2,06^{\mathrm{a}}$ & $2,15^{\mathrm{a}}$ & $2,28^{\mathrm{a}}$ & $2,18^{\mathrm{a}}$ \\
& & $(-1,45)$ & $(6,36)$ & $(11,04)$ & $(17,33)$ & $(12,13)$ \\
& & $(-18,43)$ & $(-15,70)$ & $(4,93)$ & $(0,37)$ & $(0,48)$ \\
\hline
\end{tabular}

Valores dentro de una misma columna con diferente letra difieren significativamente $(\mathrm{p}<0,05)$. Valores entre paréntesis representan la diferencia en porcentaje del valor de $\mathrm{EN}_{\mathrm{L}}$ del alimento obtenido por la ecuación basada en la producción de gas con respecto al modelo NRC (2001) / Values within the same column with different letter are significantly different $(\mathrm{p}<0.05)$. Values in parenthesis represent the difference in percentage of the $\mathrm{NE}_{\mathrm{L}}$ value of the feed obtained by the equation based on gas production with respect to the NRC (2001) model.

Los forrajes fueron obtenidos de la Estación Experimental y el rye grass corresponde a la variedad Jumbo / Forages were obtained from the Experiment Station and rye grass corresponds to the Jumbo variety. 
Las ecuaciones evaluadas mostraron diferente precisión en la estimación del valor energético en los cinco alimentos evaluados (Cuadro 4). La ecuación 1 resultó ser más precisa en la estimación de $\mathrm{EN}_{\mathrm{L}}$ en el alimento concentrado, con 0,03 Mcal de subestimación respecto al NRC (2001), los forrajes frescos (pasto estrella, pasto ryegrass y morera), se estimaron con mayor precisión con la ecuación 3, con subestimación de 0,01 Mcal, y la ecuación 4 fue más precisa en la estimación para el ensilado de maíz, con 0,01 Mcal de error.

El rango de estimación del contenido de energía neta de lactancia calculada con el método de referencia (NRC, 2001), con respecto a las ecuaciones basadas en la producción de gas mostraron promedio general al aplicar las ecuaciones a cada alimento evaluado, con una sobrestimación mayor en la ecuación 4 en el alimento concentrado y la subestimación más alta con la ecuación 2 en pasto estrella. Las ecuaciones 1 y 2 resultaron ser las menos precisas estimando $\mathrm{EN}_{\mathrm{L}}$ al aplicar cada ecuación en los cinco alimentos. Las ecuaciones 4 y 5 fueron las ecuaciones más precisas y el valor medio lo obtuvo la ecuación 3 (Cuadro 4).

Las ecuaciones evaluadas por tipo de alimento mostraron diferente precisión en la predicción de $\mathrm{EN}_{\mathrm{L}}$, si estos se clasifican por características físicas en: forrajes frescos, ensilado y alimento concentrado. El contenido de $\mathrm{EN}_{\mathrm{L}}$ predicho en forrajes frescos de este estudio mostró imprecisión promedio menor al $1 \%$. La ecuación 1 mostró el mayor potencial predictivo en el alimento concentrado con una subestimación del 1,45 \% y el ensilado de maíz fue predicho de mejor manera con la ecuación 4 con $0,57 \%$ de error.

\section{Coeficientes de correlación lineal de Pearson y de concordancia de Lin}

Las cinco ecuaciones estudiadas al evaluar su aplicación en los cinco alimentos en estudio mostraron valores del coeficiente de correlación lineal de Pearson superiores a 0,97; los menores valores los presentaron las ecuaciones 1 y 2 , y el valor mayor de 0,99 , fue encontrado con la ecuación 4. Estos resultados indican una relación lineal $(\mathrm{p}<0,0001)$ con cambios proporcionales entre los valores de $\mathrm{EN}_{\mathrm{L}}$ estimados por el modelo del NRC y las ecuaciones basadas en la producción de gas in vitro; las diferencias en el coeficiente de correlación de Pearson fueron mínimas en las cinco ecuaciones evaluadas.

Al utilizar el coeficiente de correlación de concordancia de Lin en las cinco ecuaciones basadas en la producción de gas in vitro en los cinco alimentos (Cuadro 5), se determinó que existieron diferencias en la reproducibilidad de la estimación de $\mathrm{EN}_{\mathrm{L}}$ con respecto al modelo del NRC (2001). La ecuación 1 mostró el menor coeficiente de correlación de concordancia $(\mathrm{r}=0,66)$ y el mayor valor se encontró con la ecuación 3 con valor de $\mathrm{r}=0,92(\mathrm{p}<0,0001)$.

Cuadro 5. Coeficientes de determinación en la correlación de Pearson entre el valor estimado de energía neta de lactancia (EN calculado) por el método NRC (2001) y por cinco ecuaciones basadas en la producción de gas in vitro con licor ruminal. San José, Costa Rica. 2017.

Table 5. Coefficients of determination in the Pearson correlation between the estimated value of net energy of lactation (calculated $\mathrm{NE}_{\mathrm{L}}$ ) by the NRC (2001) model and from five equations based on in vitro gas production with ruminal fluid. San Jose, Costa Rica. 2017.

\begin{tabular}{cccccc}
\hline Coeficiente & Ecuac. 1 & Ecuac. 2 & Ecuac. 3 & Ecuac. 4 & Ecuac. 5 \\
\hline Pearson & 0,97 & 0,97 & 0,98 & 0,99 & 0,98 \\
Concordancia de Lin & $0,66 \mathrm{c}$ & $0,69 \mathrm{c}$ & $0,92 \mathrm{a}$ & $0,85 \mathrm{~b}$ & $0,88 \mathrm{~b}$ \\
\hline
\end{tabular}

Valores dentro de una misma fila con diferente letra difieren significativamente $(\mathrm{p}<0,0001)$ / Values within the same row with different letter are significantly different $(\mathrm{p}<0.0001)$. 


\section{Discusión}

Los cinco alimentos evaluados son representativos de la dieta de vacas lecheras de común uso en Costa Rica, por lo cual, los resultados encontrados son pertinentes a las condiciones de fincas lecheras en Costa Rica en condiciones similares.

La composición química de los alimentos evaluados en este estudio (Cuadro 2) son comparables con los reportes de otros estudios desarrollados en Costa Rica. El pasto estrella fue menor en proteína cruda y superior en FDN, FDA y lignina a lo reportado por Villalobos y Arce (2014), estas diferencias pueden explicarse por las diferencias en altura, clima y edad de cosecha que difirieron con las muestras evaluadas en este estudio. El ensilado de maíz coincide en su composición química al reportado por Boschini (2003). La morera se ubicó en el rango de valores reportados (Boschini-Figueroa y Vargas-Rodríguez, 2009); mientras que el pasto ryegrass fue inferior en PC, superior en carbohidratos no fibrosos y similar en los otros componentes (Villalobos y Sánchez, 2010). El alimento concentrado para vacas lecheras de este estudio coincide con lo reportado por Macaya y Rojas-Bourillón (2009).

Los valores de $\mathrm{EN}_{\mathrm{LIX}}\left(\mathrm{Mcal} \mathrm{kg}^{-1} \mathrm{MS}\right.$ ) estimados por el modelo NRC (2001) en los cinco alimentos evaluados (Cuadro 2) tuvieron correspondencia con lo reportado por otros autores, en alimento concentrado para vacas lecheras (Macaya y Rojas-Bourrillón, 2009), pasto ryegrass (Villabos y Sánchez, 2010) y pasto estrella (Villalobos y Arce, 2014); sin embargo, en ensilado de maíz presentó menor valor (Abdelhaldi, 2007) y en morera mayor contenido (Boschini-Figueroa, 2006), en referencia con los reportes consultados.

El comportamiento de la curva de producción de gas (Figura 1), fue coincidente con el contenido nutricional y las características propias de los alimentos evaluados. Las diferencias encontradas respecto al volumen producido de gas en los diferentes momentos de incubación (Cuadro 3), puede explicarse por la composición química y contenido energético de los alimentos evaluados (Cuadro 2), la curva de producción de gas se comportó en correspondencia a estas características. En los procesos de incubación de sustratos forrajeros con licor ruminal, inicia la producción de gas de forma lenta, luego de hidratarse el sustrato y ser colonizadas por microorganismos las partículas para su degradación, los componentes solubles son rápidamente fermentados (Cone et al., 1996), esto explica la cantidad de gas producido respecto al contenido de CNF que es altamente correlacionado (Getachew et al., 2004). Los alimentos ricos en CNF y bajos en FND acumularon en menor tiempo proporciones mayores del total del gas producido, que expone la causa de que el alimento concentrado acumulara 16,8\% del volumen total en las primeras $4 \mathrm{~h}$ de incubación a diferencia de pasto estrella africana, con bajo CNF, y el ensilado de maíz, bajo en azúcares, que acumularon en ese intervalo $5,4 \%$ y 4,4 \%, respectivamente del gas total producido a $48 \mathrm{~h}$ de incubación.

Las diferencias en el comportamiento de la PGIV entre el alimento concentrado y el pasto estrella, fue debido a las diferencias entre estos respecto a la fracción soluble, ya que esta es fermentada y libera energía en las primeras horas de incubación (van-Gelder et al., 2005). La concentración de CNF es altamente correlacionada con el volumen de gas producido (Getachew et al., 2002). La fracción de CNF en ensilado de maíz en forma de almidón permitió que la PGIV continuara, dado que el almidón se degrada con menos rapidez que los azúcares y más rápido que la FDN. La grasa y la proteína son pobremente correlacionadas con la producción de gas in vitro, por ser poco afectadas por la fermentación microbiana (Getachew et al., 2004). Los tratamientos blancos, incubados sin sustrato, detuvieron la PGIV a las $16 \mathrm{~h}$ de iniciado el proceso fermentativo, que se explica por el inicio de la autolisis de microorganismos que acontece al consumirse los nutrientes disponibles en el sustrato (Cone et al., 1996).

A 24 h de incubación el forraje de morera y el alimento concentrado (altos en CNF), acumularon el 91,7 y 97,4 $\%$ del total del gas producido. La relación positiva entre los CNF y la PGIV, explican estos resultados, ya que los CNF liberan mayor cantidad de energía en menor tiempo (Getachew et al., 2004).

Las altas concentraciones de FDN, FDA y lignina muestran una relación negativa entre el contenido energético y la PGIV (Haddi et al., 2003; Bakhashwain et al., 2010), lo que explica el comportamiento antagónico encontrado en 
el pasto estrella, el cual al poseer los valores más altos de FDN, FDA y lignina, y el menor contenido energético en comparación con los demás alimentos evaluados en este estudio, ya que acumuló en 24 h el 58,6 \% del total del gas producido, mantuvo relativamente constante la PGIV y no detuvo el proceso fermentativo hasta el final del ensayo.

Los alimentos con mayor contenido de FDN produjeron los menores volúmenes de gas, ya que a mayor concentración de FDN se reduce la PGIV (Kamalak et al., 2005); sin embargo, se debe tener en consideración que la relación existente entre el contenido de FDN y la amplitud de este efecto varía entre especies y, en gramíneas, la influencia es mucho mayor que en leguminosas (Getachew et al., 2004), lo cual es consistente con lo encontrado en este estudio. El comportamiento de la curva de PGIV en los alimentos evaluados sugiere relaciones entre el metabolismo energético en animales rumiantes asociados a características como la degradación de la materia seca, así la morera de este estudio siguió el mismo patrón de la curva de degradación de la materia seca (BoschiniFigueroa, 2001), ya que la morera hastas las 24 h acumuló 91,68 \% del total del gas producido.

La PGIV y la respectiva cuantificación del volumen del gas producido se relaciona con la cinética de la fermentación de los alimentos y su digestibilidad (Getachew et al., 1998; Getachew et al., 2004). La interpretación de la curva de producción de gas brinda elementos para la evaluación de alimentos para rumiantes dada la emulación de las condiciones ruminales, los alimentos con acumulación de mayores volúmenes de gas en tiempo reducido pueden correlacionarse con el aumento en el consumo de materia seca, tasa de pasaje, mayor aporte energético y mejora productiva.

La producción de gas fue coincidente con la concentración energética, a 24 h de incubación con $0,5 \mathrm{~g}$ de sustrato, fue posible diferenciar el contenido energético de cada alimento evaluado. A partir de la curva de producción de gas (Figura 1) es posible conocer el comportamiento de la degradación de materia seca, los alimentos evaluados ordenados de forma ascendente respecto al contenido de $\mathrm{EN}_{\mathrm{L}}$ obtenido por el modelo NRC (Cuadro 2), coincidieron en el orden observado en la acumulación de gas in vitro a 24 h de incubación (Cuadro 3), este comportamiento sugiere una robusta relación entre la acumulación de gas in vitro de los sustratos a 24 h de incubación y el contenido de energía neta de lactancia.

No hay reportes de producción de gas en Cynodon nlemfuensis, Morus alba y Lolium perenne en la literatura consultada. La acumulación de gas producido a 24 h de incubación de plantas de diferente especie, pero análogas en su composición química a Cynodon nlemfuensis y Morus alba, mostraron correspondencia al volumen de gas producido por Pennisetum purpureum y Phaseolus mungo, respectivamente (Krishnamoorthy et al., 1995), el valor obtenido en el ensilado de maíz fue coincidente al reportado por Saricicek (2010), que podrían corroborar la influencia de la composición química en la PGIV de alimentos congruentes en su composición.

El comportamiento de la curva de producción de gas de los alimentos evaluados (Figura 1) indicó relaciones entre la PGIV y su composición, que se concretó al aplicar ecuaciones derivadas de la PGIV para estimar el contenido de $\mathrm{EN}_{\mathrm{L}}$ (Cuadro 4). Los alimentos con mayor contenido de fibra en detergente neutro y mayor contenido de carbohidratos no fibrosos (Cuadro 1), acumularon en mayor proporción el volumen de gas producido en intervalos de tiempo menores, la mayor liberación de nutrientes derivados de la fracción soluble sucede en las primeras horas de incubación (van-Gelder et al., 2005). Alimentos ricos en la fracción soluble, carbohidratos no fibrosos y azúcares, produjeron gas con mayor intensidad y acumularon mayor volumen en menor tiempo. Son los componentes solubles los que luego de la incubación son rápidamente fermentados, luego existe un cambio gradual hacia la fermentación de fracciones insolubles, que requieren previamente hidratarse y ser colonizadas y finaliza el proceso fermentativo con el reciclaje de la población microbiana y no así por la fermentación de alimento (Cone et al., 1997).

Las ecuaciones basadas en la producción de gas in vitro y la aplicación del modelo del NRC (2001) para la estimación de energía neta de lactancia, identificaron al pasto estrella y el alimento concentrado, con el menor y mayor valor de energía neta de lactancia, respectivamente. Las ecuaciones 1 y 2 (Menke y Steingass, 1988) separaron en tres grupos a los alimentos respecto al contenido de $\mathrm{EN}_{\mathrm{L}}$; las ecuaciones 3 y 4 (Seker, 2002) los clasificó en cuatro grupos y la ecuación 5 (Sallam et al., 2007) agrupó en igual número de grupos que la aplicación del modelo NRC (2001). 
La aplicación de la ecuación 3, fue más precisa en este estudio en morera con 0,07 que en alfalfa con -0,17 Mcal $\mathrm{kg}^{-1}$ MS (Seker, 2002), ambos equivalentes en composición química; en el alimento concentrado fue más preciso el uso de la ecuación 1 que lo encontrado por (Seker, 2002) que sobremestimó en 0,34 Mcal kg MS ${ }^{-1}$, utilizando digestibilidad in vivo, comparativo diferente al usado en el presente estudio.

La configuración de los algoritmos basados en la producción de gas in vitro utilizados para predecir el contenido energético en alimentos para rumiantes, incorporan elementos poco relacionados con la PGIV como la proteína cruda y el extracto etéreo (Menke y Steingass, 1988; Getachew et al., 2004), dada la necesidad de disminuir la influencia del contenido de PGIV sobre el valor de energía predicho, en este estudio se observó diferencias en precisión acorde a la consideración de elementos de la composición química considerados, en estos algoritmos (Cuadro 1). La ecuación 3 precisa en la predicción de $\mathrm{EN}_{\mathrm{L}}$ en forrajes frescos; está planteada con base en el contenido de extracto etéreo. La ecuación 4 precisa en ensilado de maíz, considera proteína cruda y extracto etéreo, y la ecuación 1 eficiente en la predicción en alimentos concentrados, está configurada con el contenido de proteína cruda, esta aseveración puede relacionarse con lo planteado, sin embargo, requiere de un análisis más profundo que considere la influencia del nutriente usado en el algoritmo y el tipo de alimento en estudio.

Los resultados de correlación de Pearson encontrados fueron levemente superiores a los reportados en los experimentos del cual se originaron estas ecuaciones, $\mathrm{r}^{2}$ de 0,94 en la ecuación 1 y 0,82 en la ecuación 2 (Menke y Steingass, 1988), sin embargo, puede destacarse que el número de muestras 200 y 150, respectivamente, generaron mayor heterogeneidad de los valores, amplitud y representatividad de la población estudiada en comparación al número menor de muestras del presente estudio. Con poblaciones más específicas y menor número de muestras, con similar cuantía a la población evaluada en este estudio, los coeficientes de determinación para la ecuación 3 (Seker, 2002) de 35,9 \% y 66,0 \% de $\mathrm{r}^{2}$ ajustado en la ecuación 4 (Seker, 2002) fueron inferiores a los encontrados en el presente estudio (Cuadro 4).

La aplicación de la correlación de concordancia (Lin, 1989) mostró mayor correspondencia que el uso de correlación lineal de Pearson (1895), como ejemplo (Cuadro 5) las ecuaciones 1 y 2 expresaron diferencias respecto al valor de referencia de $-18,43$ y $-15,70 \%$, respectivamente, el coeficiente de determinación de la correlación lineal de Pearson fue de 0,97 y la correlación de concordancia de Lin de 0,66 y 0,69, estos resultados (Cuadro 5) sugieren que la reproducibilidad de métodos mejora su evaluación mediante la correlación de concordancia de Lin, la correlación de Pearson sobreestimó el desempeño predictivo de las ecuaciones basadas en la PGIV y el método $\mathrm{NRC}$ para determinar $\mathrm{EN}_{\mathrm{L}}$. El modelo de regresión o el coeficiente de correlación son insuficientes o incorrectos en la evaluación de concordancia y fiabilidad al aplicar dos o más métodos (Carrasco y Jover, 2004), para comparar diferentes métodos midiendo la misma variable es más apropiado el uso del índice de concordancia de Lin que la correlación de Pearson, este último puede expresar coeficientes de determinación muy altos, que al graficarse son detectables diferencias importantes entre métodos (Zar, 2010).

La ecuación 3, de forma general, mostró un índice de concordancia mayor y puede aplicarse para estimar la $\mathrm{EN}_{\mathrm{L}}$ en los cinco alimentos evaluados en este estudio, sin embargo, al aplicar ecuaciones específicas en alimentos agrupados por sus características físicas se logró mejorar la sensibilidad de la predicción de las ecuaciones, en pastos y forrajes frescos (pasto estrella, pasto ryegrass y morera) la ecuación 3 fue la más precisa $(0,27,0,62$ y $0,55 \%$ respectivamente), en ensilado de maíz, forraje fermentado, la ecuación 4 obtuvo el mejor desempeño predictivo $(0,57 \%)$, y en el alimento concentrado la predicción más precisa la obtuvo la ecuación 1 con error de $-1,43 \%$ (Cuadro 4). Este comportamiento ha sido documentado en estudios anteriores, que indican especificidad de algunas ecuaciones a determinado tipo de alimento o sustrato en los que el algoritmo es desarrollado o aplicado al considerar la PGIV para predecir contenido energético o digestibilidad (Menke y Steingass, 1988; Seker, 2002; VDLUFA, 2012).

Las divergencias en precisión de la estimación del contenido de $\mathrm{EN}_{\mathrm{L}}$, pudo deberse a las diferencias en las condiciones en las que se desarrollaron los experimentos, el tipo de inóculo y concentración del sustrato, así como a 
las diferencias de composición química (Cone et al., 1996), en la PGIV también influye que el inóculo sean excretas secas o fluido ruminal, la especie animal del que se obtiene el inóculo, el sustrato evaluado (Cone et al., 1996; vanGelder et al., 2005; Saricicek, 2010; Boga et al., 2014), el tipo de dieta basal del animal donante, su adaptación a esta y el tiempo para obtener el inóculo (Cone et al., 1996), y las condiciones de laboratorio (Cornou et al., 2013), por lo que la aplicación de ecuaciones basadas en la PGIV deben considerar diversas fuentes de error que incidirán sobre el poder predictivo.

\section{Conclusiones}

La técnica de medición de la producción de gas in vitro y la aplicación de ecuaciones fueron métodos confiables para predecir el contenido de energía neta de lactancia en los alimentos propios de dietas de vacas lecheras evaluados en este estudio. El uso de la ecuación 3 de forma global fue la más precisa y predijo el contenido de energía neta de lactancia. Específicamente a pastos y forrajes frescos la ecuación 3, fue más precisa para predecir el contenido de energía neta de lactancia; mientras que en el alimento en concentrado la ecuación 1, y en ensilado de maíz la ecuación 4.

\section{Agradecimientos}

El primer autor agradece al Servicio Alemán de Intercambio Académico (DAAD) y su programa Regional para Centroamérica y el Caribe por la beca recibida, a Aníbal Montiel y Telémaco Talavera y demás compañeros por su respaldo, a la Universidad Nacional Agraria y su Sede Regional Juigalpa, a la Universidad de Costa Rica, al personal de la Estación Experimental Alfredo Volio Mata y Centro de Investigación en Nutrición Animal, y al PPCARN con énfasis en Nutrición Animal.

\section{Literatura citada}

Abdelhadi, L. 2007. Los silajes en la producción animal: importancia de la calidad. En: R. Trejos et al., editores, Memoria XI Seminario Manejo y utilización de pastos y forrajes en sistemas de producción animal. UPEL, Barquisimeto, VEN. p. 114-131.

AOAC (Association of Official Agricultural Chemists). 2006. Official methods of analysis. 18 ${ }^{\text {th }}$ ed. Rev. 1. AOAC Int., Gaithersburg, MD, USA.

AOCS (American Oil Chemists Society). 2005. Official Procedure. Approved Procedure Am 5-04, Rapid determination of oil/ fat utilizing high temperature solvent extraction. AOCS, Urbana, IL, USA.

Bakhashwain, A., S.M.A. Sallam, and A. Allam. 2010. Nutritive value assessment of some Saudi Arabian foliages by gas production technique in vitro. JKAU: Met., Env. Arid Land Agric. Sci. 21:65-80. 2010. doi:10.4197/Met.21-1.5

Boga, M., S. Yurtseven, U. Kilic, S. Aydemir, and T. Polat. 2014. Determination of nutrient contents and in vitro gas production values of some legume forages grown in the Harran Plain saline soils. Asian-Australas. J. Anim. Sci. 27:825-831. doi:10.5713/ajas.2013.13718

Boschini, C. 2003. Características físicas y valor nutritivo del ensilaje de morera (Morus alba) mezclado con forraje de maíz. Agron. Mesoam. 14:51-57. doi:10.15517/am.v14i1.11988 
Boschini-Figueroa, C. 2001. Degradabilidad in situ de la materia seca, proteína y fibra del forraje de morera (Morus alba). Agron. Mesoam. 12:79-87. doi:10.15517/am.v12i1.17290

Boschini-Figueroa, C. 2006. Nutrientes digeribles, energía neta y fracciones proteicas de la morera (Morus alba) aprovechables en vacas lecheras. Agron. Mesoam. 17:141-150. doi:10.15517/am.v17i2.5154

Boschini-Figueroa, C., y C.F. Vargas-Rodríguez. 2009. Rendimiento y calidad de la morera (Morus alba) fertilizada con nitrógeno, fósforo y potasio. Agron. Mesoam. 20:285-296. doi:10.15517/am.v20i2.4945

Carrasco, J.L., y L. Jover. 2004. Métodos estadísticos para evaluar la concordancia. Med. Clin. 122(Supl 1):28-34.

Cone, J., A. Van-Gelder, and F. Driehuis. 1997. Description of gas production profiles with a three-phasic model. Anim. Feed Sci. Technol. 66:31-45. doi:10.1016/S0377-8401(96)01147-9

Cone, J., A. Van-Gelder, G. Visscher, and L. Oudshoom. 1996. Influence of rumen fluid and substrate concentration on fermentation kinetics measured with a fully automated time related gas production apparatus. Anim. Feed Sci. Technol. 61:113-128. doi:10.1016/0377-8401(96)00950-9

Cornou, C., I. Drejer, I. Hindrichsen, H. Worgan, E. Bakewell, D. Yáñez, L. Abecia, F. Tagliapietra, M. Cattani, C. Ritz, and H. Hansen. 2013. A ring test of a wireless in vitro gas production system. Anim. Prod. Sci. 53:585-592. doi:10.1071/ AN12091

Elghandour, M.M.Y., J.C. Vázquez, A.Z.M. Salem, A.E. Kholif, M.M. Cipriano, L.M. Camacho, and O. Márquez. 2017. In vitro gas and methane production of two mixed rations influenced by three different cultures of Saccharomyces cerevisiae. J. Appl. Anim. Res. 45(1):389-395. doi:10.1080/09712119.2016.1204304

Elmenofy, E.K., M.I. Bassiouni, E.B. Belal, H.M. A. Gaafar, E.M. Abdel-Raouf, and S.A. Mahmoud. 2012. Improving the nutritive value of ensiled green rice straw 2- In vitro gas production. Nat. Sci. 10(12):86-91.

Getachew, G., M. Blümmel, P. Makkar, and K. Becker. 1998. In vitro gas measuring techniques for assessment of nutritional quality of feeds: a review. Anim. Feed Sci. Technol. 72:261-281. doi:10.1016/S0377-8401(97)00189-2

Getachew, G., P. Makkar, and K. Becker. 2002. Tropical browses: contents of phenolic compounds, in vitro gas production and stoichiometrical relationship between short chain fatty acid and in vitro gas production. J. Agric. Sci. 139:341-352. doi:10.1017/S0021859602002393

Getachew, G., P. Robinson, E. De-Peters, and S. Taylor. 2004. Relationships between chemical composition, dry matter degradation and in vitro gas production of several ruminant feeds. Anim. Feed Sci. Technol. 111:57-71. doi:10.1016/ S0377-8401(03)00217-7

Haddi, M., E. Filacorda, K. Meniai, F. Rollin, and P. Susmel, P. 2003. In vitro fermentation kinetics of some halophyte shrubs sampled at three stages of maturity. Anim. Feed Sci. Technol. 104:215-225. doi:10.1016/S0377-8401(02)00323-1

Kamalak, A., O. Canbolat, Y. Gurbuz, and O. Ozay. 2005. Comparison of in vitro gas production technique with in situ nylon bag technique to estimate dry matter degradation. Czech J. Anim. Sci. 50(2):60-67. doi:10.17221/3996-CJAS

Krishnamoorthy, U., H. Soller, H. Steingass, and K.H. Menke. 1995. Energy and protein evaluation of tropical feedstuffs for whole tract and ruminal digestion by chemical analyses and rumen inoculum studies in vitro. Anim. Feed Sci. Technol. 52:177-188. doi:10.1016/0377-8401(95)00734-5

Licitra, G., T.M. Hernández, and P.J. Van-Soest. 1996. Standardization of procedures for nitrogen fractionation of ruminant feeds. Anim. Feed Sci. Technol. 57:347-358. doi:10.1016/0377-8401(95)00837-3

Lin, L. 1989. A concordance correlation coefficient to evaluate reproducibility. Biometrics 45:255-268. doi:10.2307/2532051 
Macaya, S., y A. Rojas-Bourillón. 2009. Uso de granos secos con solubles (DDGS) provenientes de la destilería del maíz en suplementos para vacas lactantes en pastoreo de Estrella Africana (Cynodon nlemfuensis). Agron. Costarricense 33:237248.

Menke, K., and H. Steingass. 1988. Estimation of the energetic feed value obtained from chemical analysis and in vitro gas production using rumen fluid. Anim. Res. Dev. 28:7-55.

Muetzel, S., C. Hunt, and M.H. Tavendale. 2014. A fully automated incubation system for the measurement of gas production and gas composition. Anim. Feed Sci. Technol. 196:1-11. doi:10.1016/j.anifeedsci.2014.05.016

NRC (National Research Council). 2001. Nutrients requirements in dairy cattle. $7^{\text {th }}$ ed. rev. The National Academies Press, WA, USA.

Pearson, K. 1895. Notes on regression and inheritance in the case of two parents. Proc. Royal Soc. London 58:240-242.

RF ANKOM. s.f. RF ANKOM gas production system operator`s manual. ANKOM. https://www.ankom.com/sites/default/files/ document-files/RF_Manual.pdf (accessed Jun. 16, 2019).

Sánchez, J. 2007. Utilización eficiente de las pasturas tropicales en la alimentación del ganado lechero. AVPA, VEN. http:// www.avpa.ula.ve/eventos/xi_seminario/Conferencias/Articulo-2.pdf (cosultado 16 jun. 2019).

Sallam, S.M.A., M.E.A. Nasser, A.M. El-Waziry, I.C.S. Bueno, and A.L. Abdalla. 2007. Use of an in vitro rumen gas production technique to evaluate some ruminant feedstuffs. J. Appl. Sci. Res. 3:34-41. doi:10.1016/j.anifeedsci.2005.04.034

Saricicek, B. 2010. The effect on silage quality, fermentation kinetics, gas production, in vitro energy value, in vitro dry matter and organic matter digestibility of silage of different additives. Trends Anim. Vet. Sci. 1(2):79-85.

SAS Institute Inc. 2011. SAS User's guide: Statistics (Versión 9.2 Ed.). SAS Institute Inc., Cary, NC, USA.

Seker, E. 2002. The determination of the energy values of some ruminant feeds by using digestibility trial and gas test. Rev. Med. Vet. 153(5):323-328.

Sherasia, P., M. Garg, B. Phondba, and S. Hossain. 2015. Estimation of metabolizable energy, net energy-lactation and total digestible nutrients of some ruminant feedstuffs using in vitro gas production technique. Indian J. Dairy Sci. 68:370-375. doi:10.5146/ijds.v68i4.43379

Vásquez, A. 1982. Estudio detallado de los suelos de la Estación Experimental de Ganado Lechero El Alto. Tesis LIc., Universidad de Costa Rica, San José, CRI.

van-Gelder, A., M. Hetta, M. Machado-Rodrigues, J. De-Boever, H. Den-Hartig, C. Rymer, M. van-Oostrum, R. van-Kaathoven, and J. Cone. 2005. Ranking of in vitro fermentability of 20 feedstuffs with an automated gas production technique: Results of a ring test. Anim. Feed Sci. Technol. 123-124:243-253. doi:10.1016/j.anifeedsci.2005.04.044

Van-Soest, P., J.B. Robertson, and B.A. Lewis. 1991. Methods for dietary fiber, neutral detergent fiber, and nonstarch polysaccharides in relation to animal nutrition. J. Dairy Sci. 74:3583-3597. doi:10.3168/jds.S0022-0302(91)78551-2

VDLUFA (Verband Deutscher Landwirtschaftlicher Untersuchungs- und Forschungsanstalten) (ed.). 2012. Handbuch der landwirtschaftlichen versuchs- und untersuchungmethodik (VDLUFA-Methodenbuch). Bd. III. Die chemische untersuchung von futtermitteln. VDLUFA-Verlag, Darmstadt, DEU.

Villalobos, L., y J. Arce. 2014. Evaluación agronómica y nutricional del pasto estrella africana (Cynodon nlemfuensis) en la zona de Monteverde, Puntarenas, Costa Rica. II. Valor nutricional. Agron. Costarricense 38:133-145.

Villalobos, L., y J. Sánchez. 2010. Evaluación agronómica y nutricional del pasto ryegrass perenne tetraploide (Lolium perenne) producido en lecherías de las zonas altas de Costa Rica. II. Valor nutricional. Agron. Costarricense 34:43-52. 
Yáñez-Ruiz D.R., A. Bannink, J. Dijkstra, E. Kebreab, D.P. Morgavi, P. O’Kiely, C.K. Reynolds, A. Schwarm, K.J. Shingfield, Z. Yu, and A.N. Hristov. 2016. Design, implementation and interpretation of in vitro batch culture experiments to assess enteric methane mitigation in ruminants - a review. Anim. Feed Sci. Technol. 216:1-18. doi:10.1016/j. anifeedsci.2016.03.016

Zar, J. 2010. Biostatistical analysis. $5^{\text {th }}$ ed. Prentice Hall, IL, USA. 